\title{
Comparison of the Anxiolytic Effects of Saffron (Crocus sativus. L) and Diazepam Before Herniorrhaphy Surgery: A Double Blind Randomized Clinical Trial
}

\author{
Mahdi Basiri-Moghadam, ${ }^{1}$ Arash Hamzei, ${ }^{2}$ Ali-Reza Moslem, ${ }^{3}$ Saeid Pasban-Noghabi, ${ }^{4,}$ Nematollah \\ Ghorbani, ${ }^{5}$ and Jafar Ghenaati ${ }^{6}$ \\ ${ }^{1}$ Department of Nursing, Social Development and Health Promotion Research Center, Gonabad University of Medical Sciences, Gonabad, IR Iran \\ ${ }^{2}$ Department of Anesthesiology, Gonabad University of Medical Sciences, Gonabad, IR Iran \\ ${ }^{3}$ Department of Anesthesiology, Mashhad University of Medical Sciences, Mashhad, IR Iran \\ ${ }^{4}$ Department of Nursing, Student Research Committee, Center of Talents, Gonabad University of Medical Sciences, Gonabad, IR Iran \\ ${ }^{5}$ Department of Urology, Gonabad University of Medical Sciences, Gonabad, IR Iran \\ ${ }^{6}$ Department of Basic Sciences, Gonabad University of Medical Sciences, Gonabad, IR Iran \\ "Corresponding author: Saeid Pasban-Noghabi, Department of Nursing, Student Research Committee, Center of Talents, Gonabad University of Medical Sciences, Gonabad, IR \\ Iran. E-mail: pasban_saeid@yahoo.com
}

Received 2015 June 20; Accepted 2015 November 16.

\begin{abstract}
Background: Anxiety is an unpleasant state of feeling agitation and pressure induced by the patient's fear of hospitalization, anesthesia or surgery.

objectives: The present study is aimed to compare the effects of dried extract of saffron and diazepam on soothing the preherniorrhaphy surgery anxiety.

Patients and Methods: In this double blind clinical study, during 8 months, 102 patients were studied in 2012. all the patients in intervention group $(n=50)$ received $25 \mathrm{mg}$ dried extract of saffron and participants in control group $(n=52)$ received $5 \mathrm{mg}$ oral diazepam. Level of anxiety of the patients was measured using speillberger state-trait anxiety inventory (STAI) before intervention and 3 hours after administration (immediately after entering the surgery room) filled out by the patients. The patients in the two groups were compared concerning level of anxiety before/after intervention. The two groups of participants had almost equal demographic features.

Results: According to the results, level of trait anxiety in the intervention groups decreased from $37.24 \pm 7.4$ to $34.72 \pm 7.45$ and the trend among the control group was vice versa and increased from $34.51 \pm 10.74$ to $38.8 \pm 9.97$. The data showed significant relation between level of trait anxiety before and after intervention in control and experiment groups $(\mathrm{P}=0.019)$.

Conclusions: Considering the findings, in comparison to diazepam, dried extract of saffron at $25 \mathrm{mg}$ dose is more effective on soothing anxiety.
\end{abstract}

Keywords: Presurgery Anxiety, Diazepam, Saffron (Crocus sativus L.)

\section{Background}

Anxiety is an unpleasant state of feeling agitation and pressure induced by the patient's fear of hospitalization, anesthesia or surgery. Pre-surgery anxiety stimulates sympathetic, parasympathetic and endocrine system, which leads to the increase of heart beat, blood pressure and irritability of the heart and arrhythmia consequently [1]. Compared with patients with high or low pre-surgery fear, the patients with moderate fear before operation experienced better recovery after operation. After all, it is of common good to lessen the anxiety up to moderate level as a humanistic goal [2]. Anxiety is usually high among women, patients undergoing several simultaneous operations, cancer surgery, mothers who deliver baby for the first time and those who had bad experiences of their previous surgeries
[2].

The role of anesthesiologists in consulting and prescribing pre-medicating drugs is widely acknowledged so that they can be of great effect in soothing the anxiety through prescribing some medicine as pre-medication [3]. Currently, anxiolytic effects of diazepam are exerted through gamma amino butyric acid (GABA) receptors of Landa. GABA receptors that respond to benzodiazepines are almost always found at the end of post-synopsis of central nervous system (CNS) and mainly aggregate at brain membrane [4]. Benzodiazepine and diazepam are among mostly used medicines which can be used as oral medicine as well [5]. Berbel et al. studied the effects of music and diazepam on soothing anxiety and concluded that average anxiety level before surgery was attenuated after interven- 
tion [5]. More than 2000 years age, Hippocrates, the father of western medicine, introduced more than 400 medical herbs and stated that "let the food be your medicine not the medicine as your food" [6]. Some of the medical plants have been found with anxiolytic and tranquilizing effects that can be used to lessen pre-surgery anxiety [7].

Among many, saffron (Crocus sativus L.) is one of the mostly used medical plants in Iran. In addition to a food spice, several pharmacologic effects have been found for saffron which makes it a potential medicine. This is because of the fact that small dose of saffron (100 mg saffron or $30 \mathrm{mg}$ hydro-alcohol powder of saffron) as oral medicine brings in considerable pharmacologic effects [813].

Saffron is prescribe by Indian traditional medicine (Ayurveda) as adaptogen (strengthens body against stresses such as trauma, anxiety and fatigue) [8, 9, 12].

Akhondzadeh et al. in a double-blind, placebocontrolled study suggests that at least in the short-term, saffron (30 mg/day for 16 weeks) is both safe and effective in mild to moderate Alzheimer's disease [14].

\section{Objectives}

Taking into consideration the seriousness of the issue of anxiety before surgery and the effects on recovery course, controlling immunity system, higher risk of infection, water and electrolyte imbalance, increase in protein metabolite $[2,15]$, a double blind randomized clinical trial study was conducted to evaluate the current methods for controlling anxiety and develop new medicines based on indigenous plants of Gonabad city in 2012.

\section{Patients and Methods}

This double blind randomized clinical trial, upon approval of ethics committee of Gonabad University of Medical Sciences and registering the research in Iranian Registry Clinical Trial (IRCT201205165445N3), 134 patients candidate for herniorrhaphy operation were studied and assessed. After pilot study in 10 patient (5 in intervention group and 5 in control group) sample size was obtained with comparison of formula and confidence level 95\%, margin of error $80 \%$ for each group 47 patients. That the loss probability of sample with 10 percents of sample drop, 50 samples for each group were considered. Samples were adopted by anesthesia practitioner based on the goal. The criteria for admittance in the study were expressing desire to do so by the participant, being a candidate for herniorrhaphy operation being in I and II classes of physical status of American society of anesthesiologist (ASA) [2] and age range of 18 - 50 years; only men were accepted. Participants whom were allergic to saffron, its products and tranquilizers expect for those under study were removed from the list. Finally, 16 individuals were removed from the list of 134 candidates ( 6 failed to meet the criteria and 10 backed out). During the study, 4 patients in intervention group and 3 in control group left the study after cancelation of their surgery. At follow up stage, 9 patients were removed from the study as they refused to complete the questionnaire. Therefore, 102 patients were analyzed ( 52 in control group and 50 in intervention group). The study was conducted over 8 months in 15 Khordad hospital of Gonabad, Iran and all the participants were surveyed using speillberger statetrait anxiety inventory (STAI) before taking medicine and immediately after entering surgery room. Moreover, vital signs of the patients in the ward were recorded based on their file. The study was carried out as double blind, controlled, parallel randomized clinical trial.

The participants in the control group received $5 \mathrm{mg}$ oral diazepam with $100 \mathrm{~mL}$ water $(\mathrm{n}=50)$ and the intervention group received $25 \mathrm{mg}$ of saffron powder with $100 \mathrm{~mL}$ water. Before the operation, biographical information of the patients was recorded before intervention. To ensure random selection of the participants, a table with 120 rows (001 - 120) was used to assign row number to each group randomly. Afterward, patients that met the criteria to participate in the study were inserted to the table and grouped (e.g. first 60 rows as control group and second 60 rows as intervention group). In fact, the rows of control and intervention groups had been determined when the names were added to the table. In addition, only anesthesiologist was aware for the random number tables and assignment of rows to the groups and the nurse, interviewer and the patient did not know about the grouping and type of the taken medicine. The table was kept by the researchers and they did not know about the type of medicine before assigning patients into the two groups. Pharmacologist expert prepared 120 identical capsules with capacity for 500 mg of sugar powder. In case of intervention group, the capsules were filled with $25 \mathrm{mg}$ of dried extract of saffron and $475 \mathrm{mg}$ sugar powder and in case of intervention group the capsules were filled with $5 \mathrm{mg}$ diazepam and $495 \mathrm{mg}$ sugar powder. Only the pharmacologist was aware of the contents of the capsules so that each capsule was placed in a pocket bearing a code. This code was also mentioned on top of the questionnaire by the nurse. The codes were provided to statistic analyzer for statistical analyses.

First, all the patients were examined by anesthesiologist and urology surgeon and all pre-surgery measure were taken. In addition, vital sings of the patients were recorded and STAI was filled out for the patients immediately after entering operation room. Validity and reliability of the 
questionnaire have been confirmed for Iranian society. In last study Cronbach's alpha was used to calculate the reliability of the method was validated obtained 0.9. It is comprised of two sections; section one (20 questions with very low, low, high, very high alternatives scored with 1 4 respectively) deals with surveying state anxiety mode of the participant. The second section, on the other hand, is comprised of 20 questions each of which with four alternatives, almost never, sometimes, most of time, almost always; each scored with 1 - 4 respectively and deals with trait anxiety. According to STAI and taking into account the participants' score in the questionnaire, state anxiety was ranked as none (20 - 30), trivial (31 - 42), moderate (43 - 53), and sever $(54<)$, and trait anxiety was ranked as none $(20$ - 34), trivial (35 - 45), moderate (46 - 57) and severe (57<) [15]. Afterward, total points of scores of the two sections were counted independently. Vital signs were checked by the nurse in the ward and researchers had no role in this regard. Blood pressure was measured by Microlife AGI-20 (Switzerland). The questionnaire was filled out by a nurse after, providing required training at first stage and by an anesthesiologist after providing required training at the second stage. The saffron used in the experiment was supplied from Novin zaferan company and the extract was prepared by adding $20 \mathrm{~g}$ dry tassel of saffron to $1000 \mathrm{~mL}$ distilled water, placing the solution on shacking machine for 72 hours and mixing the solution manually in specific occasions. Then, the overhead liquid was transferred into plate after centrifuging and dried on Bain-Marie at $40^{\circ} \mathrm{C}$. Afterward, the dried mass was scratched to obtain an orange red substance solvable in water and normal saline.

The performance of extraction method was $45 \%$. The participants were examined regarding the level of anxiety and vital signs and those refused to fill out the questionnaire were removed from the study.

Data was analyzed using the SPSS-11.5 (SPSS Inc, Chicago, IL, USA). Statistical tests Fisher Exact test, Mann Whitney $U, \chi^{2}$ and Independent Sample t-test were employed to determine normality of Kolmogrov Smirnov test.

\section{Results}

The study was conducted within 8 months on participants ranging age from 18 to 50 and average age of $31.12 \pm$ 10.9 years (control group) and $29.96 \pm 8.66$ years (intervention group). That was no significant relation between the two groups and the both groups were homogenous in this regard. Table 1 showed lists demographic data of the two groups.

According to Table 1, the study population is homogenous regarding demographic data. No significant differ- ence was found between the two groups regarding trait and state anxiety. But, there was a significant relationship between, level of trait anxiety in two groups after intervention $(\mathrm{P}=0.019)$. Table 2 presents comparison between state and trait anxiety after intervention. As listed in the Table 2, state anxiety, whether before and after intervention, was trivial among the participants in the both groups. However, trait anxiety was trivial and none in intervention and control groups before intervention respectively and after intervention, it was trivial in the both groups.

Significant difference was found between control and intervention groups regarding trait anxiety so that it was lower in intervention group $(\mathrm{P}=0.019)$. Mean arterial blood pressure (MAP) in the intervention and diazepam before intervention were $90.41 \pm 11.15 \mathrm{mmHg}$ and $88.5 \pm 9.28$ $\mathrm{mmHg}$ respectively and $89.5 \pm 5.13 \mathrm{mmHg}$ and $89.9 \pm 6.08$ $\mathrm{mmHg}$ after intervention respectively. Significant statistical difference was observed between the two groups regarding average blood pressure in the both groups.

\section{Discussion}

The findings showed effectiveness of saffron on lessening trait anxiety, though the reduction of state anxiety was not significant. Several studies have confirmed effects of saffron on treating depression, however, none of them have specifically focused on anxiety. On the other hand, animals have been the subjects of studies in this field to evaluate anxiolytic of diazepam.

Herron et al. discussed anxiolytic effects of diazepam through GABA receptors on animal subjects [16]. Taking into account that saffron is traditionally used as anxiolytic medicine and given its effect on lessening anxiety before surgery, the probable cause of such effects are physiologic and biologic effects of the medicine.

Shabanian et al. studied double blind clinical internship over 60 patients at the age range 14 - 48 years and compared anxiolytic effects of diazepam (5 mg in $100 \mathrm{~mL}$ water administered 2 hours before surgery) and orange blossom (100 mL administered 2 hours before surgery). Anxiety level was measured using STAI and the results confirmed reduced state anxiety after administration [17]. In Banaiyan et al. research the mean of state and trait anxiety was reduced in diazepam group. In our study, the mean of state anxiety in diazepam group was unchanged, but the mean of trait anxiety had increased. These differences may be the result of time devoted to fill out the questionnaire after the intervention and the type of surgery and the study population. In Shabanian study, questionnaire was filled out two hours after oral administration of diazepam [17]. Previous studies showed that the peak effect of oral diazepam is 1-2 
Table 1. Demographic Data of Control and Intervention Groups ${ }^{\mathrm{a}}$

\begin{tabular}{|c|c|c|c|}
\hline Demographic Data & Intervention & Control & P Value \\
\hline History of surgery & & & 0.16 \\
\hline Yes & $22(6.21)$ & $29(4.28)$ & \\
\hline No & $28(5.27)$ & $23(5.22)$ & \\
\hline Education & & & 0.29 \\
\hline Secondary school & $11(7.10)$ & $12(8.11)$ & \\
\hline High school & $8(8.7)$ & $11(8.10)$ & \\
\hline Higher education & $15(7.14)$ & $18(8.17)$ & \\
\hline Occupation & & & 0.82 \\
\hline Employee & $9(8.8)$ & $8(8.7)$ & \\
\hline Business man & $30(4.29)$ & $30(4.29)$ & \\
\hline Others & $11(8.10)$ & $14(8.13)$ & \\
\hline
\end{tabular}

${ }^{\mathrm{a}}$ Values are expressed as No. (\%).

Table 2. Average State and Trait Anxiety Before and After Intervention ${ }^{a}$

\begin{tabular}{rrr}
\hline Group & Intervention & Control \\
\hline Before intervention & & \\
State anxiety & $34.32 \pm 9.09$ & $37.52 \pm 9.21$ \\
Trait anxiety & $37.24 \pm 7.4$ & $34.51 \pm 10.74$ \\
After intervention & & 0.1 \\
State anxiety & $36.44 \pm 7.93$ & $37.65 \pm 8.08$ \\
Trait anxiety & $34.72 \pm 7.45$ & $38.86 \pm 9.97$ \\
\hline
\end{tabular}

${ }^{\mathrm{a}}$ Values are expressed as mean $\pm \mathrm{SD}$.

hours after drug administration [18]. But, in our study according to the anesthesiologist that to three hours before surgery drinking water (drug) is permissible for adults, we prescribed for the two groups this drug three hours before surgery, while in Shabanian study 2 hours before the surgery patients had received diazepam [17].

With an extensive literature review researchers could not find a similar study. Emotional reactions to stressful situations are placed in a wide range of joy and happiness, common excitement, anxiety, anger, frustration and depression. Anxiety is the most common response to stressful stimuli. Anxiety means unpleasant excitement that we all have some degree of it in the form of words, such as concern and fear. But the common human response to failure is active aggression. However, the reverse behaviors, i.e. detachment and isolation are also common. If the stressful situation continues and the person may not succeed in resolving it the depth of the detachment may increase and cause depression [19].

About $25 \%$ - 50\% of depressed youth have comorbid anxiety disorders and about 10\% - 15\% of anxious youth have depression [20]. Studies on the relationship between depression and anxiety have emphasized one of three different conceptual models: anxiety and depression as a continuum in which anxiety and depressive symptoms overlap and blend together; anxiety and depression as distinct illnesses with clear boundaries; and a mixed anxietydepressive disorder as a distinct disorder differing from the pure forms of these disorders [21].

Many studies about the antidepressant effects of saffron has been done on human, that the following can be noted: Shahmansouri et al. in their study showed that short-term treatment with saffron capsules (30 mg daily for six weeks) and fluoxetin (40 mg daily for six weeks) had the same antidepressants effects in patients [22]. In another study, the effect of saffron (10 mg essence of saffron) 
was measured as an anti-depression factor and the results were compared with impiramine (30-100 mg). The results showed equal efficiency of imipramine and saffron on outgoing depression patients (trivial moderate anxiety) and no side effect was observed in the subject [23]. Our study examined the effect of anti-anxiety of saffron and showed that the mean of trait anxiety had reduced.

Hosseinzade and Noraei studied the anxiolytic and sleep inducing effects of saffron and the compounds (Safranal). Their findings showed that crocins has no anxiolytic effect, although essences of saffron and safranal at high dose (more than 0.15 and $0.35 \mathrm{mg}$ ) have anxiolytic effects [24]. The anti-effects of saffron and diazepam were subject of another study that was planned to examine the anxiolytic effects of crocins on rodents. To this end, the light/dark test was adopted. Crocin at a dose less than that may influence motor activity (50 mg/kg) and diazepam (1.5 $\mathrm{mg} / \mathrm{kg}$ ) both increased the delay to enter the dark compartment an increased the time spent in light chamber among the rat. On the other end, small doses of crocins (15 - 30 $\mathrm{mg} / \mathrm{kg}$ ) made no considerable change in the subjects' behavior [25].

Thus, according to these studies, we can say that our research is consistent with other researches in the field of depression. Saffron has crocetin as free compound and trivial amount of pigments anthocyanin, $\alpha$ - and $\beta$-carotene, zeaxanthin $[26,27]$. The saffron and crocetin are keen to $\sigma 1$ (sigma-1) receptor [28]. Ligands $\sigma 1$ of the receptor shows anti-cancer, memory/learning/cognition improving, antidepression, anti-psychosis, anxiolytic and neurons protecting properties. Therefore, the anti-anxiety effects of the dried extract of saffron are probably due to its effect on this receptor. In addition, affinity and connection of saffron, crocins and crocetin to NMDA (N-methyl-D-aspartate) receptor, agonistic effects on GABAA receptor complex of benzodiazepam and opioid receptor have been studied in other works [29]. Thus, taking into consideration that diazepam induces its effect through GABAA receptor, thus the same path is taken saffron essence powder to induce anxiolytic effects. A limitation in conducting this study was financial limitations for preparing the expensive saffron capsules. For future studies it is recommended to focus separately on different elements of saffron through clinical assessments. It appears that saffron, as a traditional indigenous medical plant is good choice for controlling anxiety before surgery, but further clinical trials are recommended to use saffron as anti-anxiety drug.

\section{Acknowledgments}

The author hereby expresses their gratitude toward the members of the committee and research affairs manage- ment and department. In addition, we would like thank all the patients and colleagues who contributed in conducting this study.

\section{Footnotes}

Authors' Contribution: Mahdi Basiri-Moghadam, Arash Hamzei, Saeid Pasban-Noghabi, Ali-Reza Moslem, Jafar Ghenaati and Nematollah Ghorbani attest to having approved the final manuscript. Additionally, for research reports, brief reports, and technical communications involving more than one author, at least two authors, Mahdi Basiri-Moghadam and Saeid Pasban-Noghabi, attest to having reviewed the original study data and data analysis as well as attest the integrity of the original data and the analysis reported in this manuscript. One author, Saeid PasbanNoghabi, has also been designated as the archival author responsible for maintaining the study records.

Funding/Support: The present study was financial supported by the Student Research Committee of the Gonabad University of Medical Sciences (project code 90/26) and the main researcher was Saeid Pasban-Noghabi.

\section{References}

1. Ghardashi F. Factors affecting preoperative anxiety [in Persian]. Koomesh. 2007;8(3):123-30.

2. Miller RD, Eriksson LI, Fleisher LA. Miller's Anesthesia. 7 ed. Philadelphia: Churchill Livingstone; 2009. pp. 651-5.

3. Rostaminejadi AB, Karimi Z. A study on oral ketamine premedication effects on anxiety of parentral separation in 2-7 Y/O children for elective surgery [in Persian]. Arak Med Univ J. 2002;5(3):36-41.

4. Miller RD, Pardo MC. Basic of anesthesia. 6 ed. Philadelphia: W.B. Saunders; 2011. pp. 137-8.

5. Berbel P, Moix J, Quintana S. [Music versus diazepam to reduce preoperative anxiety: a randomized controlled clinical trial]. Rev Esp Anestesiol Reanim. 2007;54(6):355-8. [PubMed: 17695946].

6. Schultes RE. The kingdom of plants. In: Thomson WAR, editor. Medicines from the earth. New York: McGraw-Hill; 1978. p. 208.

7. Movafegh A, Alizadeh R, Hajimohamadi F, Esfehani F, Nejatfar M. Preoperative oral Passiflora incarnata reduces anxiety in ambulatory surgery patients: a double-blind, placebo-controlled study. Anesth Analg. 2008;106(6):1728-32. doi: 10.1213/ane.0b013e318172c3f9. [PubMed: 18499602].

8. Verma SK, Bordia A. Antioxidant property of Saffron in man. Indian J Med Sci. 1998;52(5):205-7. [PubMed: 9808914].

9. Akhondzadeh S, Tahmacebi-Pour N, Noorbala AA, Amini H, FallahPour H, Jamshidi AH, et al. Crocus sativus L. in the treatment of mild to moderate depression: a double-blind, randomized and placebocontrolled trial. Phytother Res. 2005;19(2):148-51. doi:10.1002/ptr.1647. [PubMed: 15852492].

10. Akhoundzadeh S, Falahpour H, Afkham K, Jamshidi AH, Khalighi Cigaroudi F, Miller LG. A comparative trial of Crocus sativus L.(saffron) and imipramine in mild to moderate depression. Focus Altern Complement Ther. 2005;10(1):22-3.

11. Noorbala AA, Akhondzadeh S, Tahmacebi-Pour N, Jamshidi AH. Hydro-alcoholic extract of Crocus sativus L. versus fluoxetine in the treatment of mild to moderate depression: a double-blind, 
randomized pilot trial. J Ethnopharmacol. 2005;97(2):281-4. doi: 10.1016/j.jep.2004.11.004. [PubMed: 15707766].

12. Kianbakht S, Ghazavi A. Evaluation of immunological and hematological effects of saffron in men. Ethnopharmacologia. 2005;36:78-83.

13. Agha-Hosseini M, Kashani L, Aleyaseen A, Ghoreishi A, Rahmanpour $\mathrm{H}$, Zarrinara AR, et al. Crocus sativus L. (saffron) in the treatment of premenstrual syndrome: a double-blind, randomised and placebo-controlled trial. BJOG. 2008;115(4):515-9. doi: 10.1111/j.14710528.2007.01652.x. [PubMed: 18271889].

14. Akhondzadeh S, Sabet MS, Harirchian MH, Togha M, Cheraghmakani $\mathrm{H}$, Razeghi S, et al. Saffron in the treatment of patients with mild to moderate Alzheimer's disease: a 16-week, randomized and placebocontrolled trial. J Clin Pharm Ther. 2010;35(5):581-8. doi: 10.1111/j.13652710.2009.01133.x. [PubMed: 20831681].

15. Fathi-Ashtiani A, Dastani M. Psychological test. 3 ed. Tehran: Be'sat Press; 2009. pp. 337-44.

16. Herron ME, Shofer FS, Reisner IR. Retrospective evaluation of the effects of diazepam in dogs with anxiety-related behavior problems.J Am Vet Med Assoc. 2008;233(9):1420-4. doi: 10.2460/javma.233.9.1420. [PubMed: 18980494].

17. Shabanian G, Rasti-Boroujeni A, Shirmardi M. Comparison of the effect of Citrus aurantium and diazepam on preoperative anxiety [in Persian]. J Shahrekord Univ Med Sci. 2009;10(4):13-8.

18. Schull PD. Nursing spectrum drug handbook. 5 ed. New York: McGraw-Hill; 2009. pp. 339-40.

19. Naebi-Nyia AS, Salary S, Modarres-Gharavi M. Studying the relationship between adult attachment style to parents with stress, anxiety and depression. QJFundamentals Ment Health. 2011;13(2):194-202.

20. Axelson DA, Birmaher B. Relation between anxiety and depressive disorders in childhood and adolescence. Depress Anxiety. 2001;14(2):6778. [PubMed: 11668659].

21. Shores MM, Glubin T, Cowley DS, Dager SR, Roy-Byrne PP, Dunner DL. The relationship between anxiety and depression: a clinical comparison of generalized anxiety disorder, dysthymic disorder, panic disor- der, and major depressive disorder. Compr Psychiatry. 1992;33(4):23744. [PubMed: 1643864].

22. Shahmansouri N, Farokhnia M, Abbasi SH, Kassaian SE, Noorbala Tafti AA, Gougol A, et al. A randomized, double-blind, clinical trial comparing the efficacy and safety of Crocus sativus $L$. with fluoxetine for improving mild to moderate depression in post percutaneous coronary intervention patients. J Affect Disord. 2014;155:216-22. doi 10.1016/j.jad.2013.11.003. [PubMed: 24289892].

23. Akhondzadeh S, Fallah-Pour H, Afkham K, Jamshidi AH, KhalighiCigaroudi F. Comparison of Crocus sativus L. and imipramine in the treatment of mild to moderate depression: a pilot double-blind randomized trial [ISRCTN45683816]. BMC Complement Altern Med. 2004;4:12. doi: 10.1186/1472-6882-4-12. [PubMed: 15341662].

24. Hosseinzadeh H, Noraei NB. Anxiolytic and hypnotic effect of Crocus sativus aqueous extract and its constituents, crocin and safranal, in mice. Phytother Res. 2009;23(6):768-74. doi: 10.1002/ptr.2597. [PubMed: 19142981].

25. Pitsikas N, Boultadakis A, Georgiadou G, Tarantilis PA, Sakellaridis $\mathrm{N}$. Effects of the active constituents of Crocus sativus L., crocins, in an animal model of anxiety. Phytomedicine. 2008;15(12):1135-9. doi: 10.1016/j.phymed.2008.06.005. [PubMed: 18693098].

26. Abdullaev FI. Cancer chemopreventive and tumoricidal properties of saffron (Crocus sativus L.). Exp Biol Med (Maywood). 2002;227(1):20-5. [PubMed: 11788779].

27. Tarantilis PA, Polissiou MG. Isolation and identification of the aroma components from saffron (Crocus sativus). J Agric Food Chem. 1997;45(2):459-62. doi: 10.1021/jf960105e.

28. Lechtenberg M, Schepmann D, Niehues M, Hellenbrand N, Wunsch B, Hensel A. Quality and functionality of saffron: quality control, species assortment and affinity of extract and isolated saffron compounds to NMDA and sigma1 (sigma-1) receptors. Planta Med. 2008;74(7):764-72. doi: 10.1055/s-2008-1074535. [PubMed: 18496783].

29. Kianbakht S. A systematic review on pharmacology of saffron and its active constituents. J Med Plants. 2008;7(28):1-27. 